\title{
NIHSS and acute complications after anterior and posterior circulation strokes
}

This article was published in the following Dove Press journal:

Therapeutics and Clinical Risk Management

29 February 2012

Number of times this article has been viewed

\section{Mathieu Boone' Jean-Marc Chillon ${ }^{2}$ \\ Pierre-Yves Garcia' \\ Sandrine Canaple' \\ Chantal Lamy' \\ Olivier Godefroy ${ }^{1,3}$ \\ Jean-Marc Bugnicourt ${ }^{1,2,3}$}

'Department of Neurology, Amiens University Hospital, Amiens, France, ${ }^{2}$ INSERM ERI- I 2, and University of Picardie, ${ }^{3}$ Laboratory of Functional Neurosciences and Pathology (EA 4559), Amiens, France

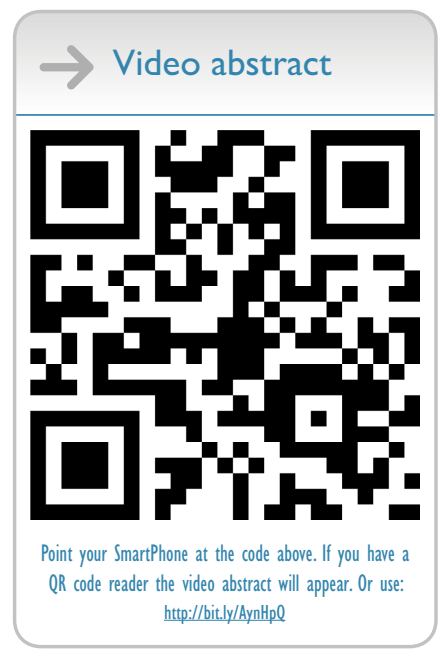

Correspondence: Jean-Marc Bugnicourt Service de Neurologie, $\mathrm{CHU}$ Amiens, France, Place Victor Pauchet, F-80054 Amiens Cedex I, France $\mathrm{Tel}+33322668240$

Fax +33322668244

Email bugnicourt.jean-marc@chu-amiens.fr
Background: The purpose of this study was to determine whether the National Institutes of Health Stroke Scale (NIHSS) score was associated with inhospital neurological and medical complications (NMC) in patients with posterior circulation infarction.

Methods: This retrospective study included all patients admitted to our stroke unit during a one-year period ( $\mathrm{n}=289$ ). NMC included neurological deterioration (ie, worsening by 4 points or more of the NIHSS score during the hospital stay) and all other medical complications based on what was recorded in the patients' charts.

Results: Seventy-nine patients (27\%) experienced NMC. In posterior circulation infarction patients $(\mathrm{n}=90)$, patients with NMC had a higher baseline NIHSS score (10.9 versus 2.2, $P=0.004)$ and a baseline NIHSS score $>2(78 \%$ versus $36 \%, P=0.003)$. In stepwise logistic regression, an NIHSS score $>2$ (odds ratio: $8.2 ; 95 \%$ confidence interval: $1.64-41.0 ; P=0.01$ ) was associated with NMC. Similar results were observed for anterior circulation infarction patients but with a higher cutoff value for NIHSS score.

Conclusion: In ischemic stroke patients, an increased baseline NIHSS score was associated with an increased risk of NMC. This association applied to anterior-circulation as well as posterior circulation stroke, although zero on the NIHSS for posterior circulation stroke does not mean the absence of NMC during hospitalization. The clinical significance of these findings requires further evaluation in larger prospective studies.

Keywords: acute, stroke, rating scales, complications

\section{Introduction}

During the acute phase of ischemic stroke, patients frequently experience neurological and medical complications (NMC). Post-stroke neurological event, so-called early neurological deterioration, is common, occurring in up to $40 \%$ of patients and is associated with a worse clinical outcome. ${ }^{1-3}$ Early neurological deterioration is caused by several pathophysiological mechanisms, including extension of infarction, hemorrhage, brain swelling (edema), seizure, and hydrocephalus. In addition, stroke patients can experience other medical events, such as urinary and chest infections, congestive heart failure, falls, pressure ulcer, gastrointestinal bleeding, deep venous thrombosis, and pulmonary embolism. ${ }^{2,4-6}$ These complications are a major cause of death during the acute and subacute phases of stroke. ${ }^{2}$ Despite scarce data to guide the management of these complications, it remains essential to predict these complications early in the course of ischemic stroke.

The National Institutes of Health Stroke Scale (NIHSS) is widely used as a standard instrument to evaluate the severity of a patient's neurological deficit, both in the 
emergency department and in the stroke unit. ${ }^{7}$ The NIHSS is a stroke-specific quantitative scale that examines the level of consciousness, language function, neglect, visual field, eye movements, facial palsy, motor strength, sensory function, and coordination. The examination can be performed quickly, and the NIHSS score can be assessed by neurologists as well as non-neurologists after appropriate training. ${ }^{8,9}$ This scale shows excellent reliability and validity and has been used in most stroke trials in order to evaluate neurological outcome. ${ }^{10,11}$ Furthermore, evidence exists to show that the NIHSS is associated with final outcome after a stroke in terms of length of stay, ${ }^{12}$ survival, and discharge destination. ${ }^{13}$ However, this scale is mainly weighted toward signs caused by anterior-circulation infarction. ${ }^{14}$ To date, it is still unclear whether baseline NIHSS score can also predict NMC in patients with posterior circulation infarction. The aim of this study was thus to determine whether baseline NIHSS score is associated with NMC, whatever the stroke localization.

\section{Materials and methods}

\section{Study population}

This retrospective study was carried out in the stroke unit at Amiens University Hospital and included all patients referred for an acute ischemic stroke during a one-year period. Patients with a transient ischemic attack $(n=42)$ or absence of a corresponding ischemic lesion $(n=12)$, poor initial prognosis (comatose or intubated patients; pulmonary infection at admission, $n=26$ ), patients with onset of cerebral ischemic event more than 6 hours earlier $(n=30)$, and patients with multiple infarcts affecting both anterior and posterior circulations $(n=5)$ were excluded. The remaining 289 patients were included. Cranial computed tomography and/or magnetic resonance imaging, 12-lead electrocardiography, cervical Doppler ultrasonography, transthoracic echocardiography, and standard laboratory tests were performed in all patients on admission. Transesophageal echocardiography, specialized laboratory tests, and Holter electrocardiographic monitoring were performed in selected patients.

For each patient, clinical data were prospectively collected according to a standardized protocol, ${ }^{15} \mathrm{ie}$, age, gender, cause of ischemic stroke according to the TOAST (Trial of Org 10172 in Acute Stroke Treatment) criteria ${ }^{16}$ (to which we added two well-known etiologies, ie, intracranial atherosclerotic disease and aortic atherosclerotic disease) and stroke risk factors that had been previously identified or discovered during hospitalization, including hypertension (antihypertensive treatment or systolic blood pressure $>140 \mathrm{mmHg}$ or diastolic blood pressure $>90 \mathrm{mmHg}$ prior to hospitalization), diabetes (insulin or oral antidiabetic therapy or fasting blood glucose $>7 \mathrm{mmol} / \mathrm{L}$ on two occasions during hospitalization), hypercholesterolemia (lipid lowering treatment or lowdensity lipoprotein $>1 \mathrm{~g} / \mathrm{L}$ ), coronary artery disease (defined as a known history of myocardial infarction or angina), current smoking, regular alcohol consumption (more than two alcoholic drinks daily), peripheral artery disease, and body mass index $\left(\mathrm{kg} / \mathrm{m}^{2}\right)$. Glomerular filtration rate was estimated using the four-component Modification of Diet in Renal Disease equation, which is based on age, gender, race, and serum creatinine concentration determined on admission. The presence of chronic kidney disease was defined as glomerular filtration rate $<60 \mathrm{~mL} /$ minute $/ 1.73 \mathrm{~m}^{2}$, in accordance with the National Kidney Foundation criteria. ${ }^{17}$ Furthermore, treatment before hospitalization was also recorded. Severity of stroke was assessed using the NIHSS at hospital admission and then every 6 hours during the first 72 hours and once a day after the third day. All clinical physicians who recorded the NIHSS score were certified in administration of the scale, to improve intrareliability and inter-reliability. The present study received institutional review board approval (from the Commission d'Evaluation Ethique des Recherches Non Interventionnelles, Amiens University Hospital).

\section{Definition of stroke localization}

Diagnosis of stroke was based on clinical and radiological evaluation by a stroke fellow (MB) and a stroke attending physician (JMB) regardless of symptom duration. Anterior circulation infarction was defined as an acute focal neurological deficit with at least two of the following three features: hemiparesis or hemisensory loss, and/or aphasia or other cortical dysfunction, and/or homonymous hemianopia, with a corresponding ischemic lesion on brain imaging. A diagnosis of posterior circulation infarction was based on hemiparesis or hemisensory loss and/or brainstem or cerebellar signs or isolated homonymous hemianopia, with corresponding ischemic lesion on brain imaging. ${ }^{18}$ Patients with lacunar syndromes, including pure motor stroke, pure sensory stroke, sensorimotor stroke, and ataxic hemiparesis, were diagnosed as anterior circulation infarction or posterior circulation infarction according to vascular imaging. ${ }^{19}$

\section{Definition of NMC}

During hospitalization, detailed data on NMC (including neurological and other medical events) were prospectively recorded using a standardized form for each patient. A neurological event was defined as worsening by 4 points 
or more of the NIHSS score during the hospital stay. This clinical deterioration was systematically documented by instrumental examination (brain computed tomography scan and/or magnetic resonance imaging to determine the mechanism of this complication). For other medical events, the occurrence of infectious complications was recorded prospectively. The presence of other complications was based on what was recorded in the patients' charts and according to clinical signs and diagnostic tests. Whenever needed, a specialist consultation was used to confirm a diagnosis.

\section{Statistical analysis}

Clinical variables in patients with anterior circulation infarction and posterior-circulation infarction were first compared using Student's $t$-tests for continuous variables and $\chi^{2}$ tests for categorical variables. NIHSS score was analyzed both as a continuous variable and as a categorical variable. The best cutoff value was selected by building a receiver-operating characteristic curve using the Youden index. To compare patients with and without $\mathrm{NMC}$, we then divided our population into two groups, ie, anterior circulation infarction and posterior circulation infarction. In each group, the same baseline variables were analyzed. Pertinent variables selected by univariate analysis with $P<0.1$ were tested in a backward logistic regression analysis, and adjusted odd ratios (OR) and 95\% confidence intervals (CI) were generated. $P$ values $<0.05$ were considered to be statistically significant. All statistical analyses were performed using SPSS statistical software (SPSS Inc, Chicago, IL).

\section{Results}

\section{Baseline variables}

Amongst the 289 included patients, 199 (69\%) had anterior circulation infarction and 90 had posterior circulation infarction. Demographic data and vascular risk factors did not differ between anterior circulation infarction and posterior circulation infarction patients, but baseline NIHSS scores did and were higher in anterior circulation infarction than in posterior circulation infarction (Table 1).

\section{ME during hospitalization}

Seventy-nine patients (27\%) experienced 108 NMC (Table 2). Among the NMC, ischemic stroke recurrence was the most frequent neurological event, and pneumonia and urinary tract infection was the most frequent medical complication. A tendency for higher frequency of NMC in patients with anterior circulation infarction than in patients with posterior circulation infarction $(31 \%$ versus $20 \%, P=0.065)$
Table I Baseline variables by stroke localization $(n=289)$

\begin{tabular}{|c|c|c|c|}
\hline & $\begin{array}{l}\text { ACI } \\
(n=199)\end{array}$ & $\begin{array}{l}\mathrm{PCl} \\
(n=90)\end{array}$ & $P$ value \\
\hline Age (years) & $68.0 \pm 15.4$ & $67.6 \pm 14.7$ & 0.83 \\
\hline Men & $102(5 \mathrm{I})$ & $57(63)$ & 0.07 \\
\hline \multicolumn{4}{|l|}{ Previous main risk factors } \\
\hline Hypertension & II8 (59) & $63(70)$ & 0.09 \\
\hline Diabetes mellitus & $52(26)$ & $23(26)$ & 1.00 \\
\hline Dyslipidemia & $65(33)$ & $30(33)$ & 1.00 \\
\hline Active smoking & $40(20)$ & $18(20)$ & 1.00 \\
\hline Coronary artery disease & $27(14)$ & $13(14)$ & 0.86 \\
\hline Atrial fibrillation & $39(20)$ & $10(11)$ & 0.09 \\
\hline PAD & $21(11)$ & $12(13)$ & 0.55 \\
\hline Stroke & $36(18)$ & $23(26)$ & 0.16 \\
\hline $\mathrm{BMI} \geq 25 \mathrm{~kg} / \mathrm{m}^{2}$ & $103(52)$ & $44(49)$ & 0.70 \\
\hline Alcohol consumption & $30(15)$ & $12(13)$ & 0.86 \\
\hline Chronic kidney disease & $52(26)$ & $26(29)$ & 0.67 \\
\hline \multicolumn{4}{|l|}{ Baseline NIHSS } \\
\hline NIHSS score & $7.3 \pm 7.1$ & $4.0 \pm 6.3$ & $<0.001$ \\
\hline \multicolumn{4}{|l|}{ Causes of ischemic stroke } \\
\hline Large vessel atherosclerosis & $29(15)$ & II (I2) & $0.7 \mathrm{I}$ \\
\hline Cardioembolic & $76(38)$ & $24(27)$ & 0.06 \\
\hline Lacunar & $19(10)$ & $10(11)$ & 0.68 \\
\hline Undetermined & $63(32)$ & $34(38)$ & 0.35 \\
\hline Other & $14(7)$ & $7(8)$ & 0.81 \\
\hline
\end{tabular}

Notes: Results are presented either as means \pm standard deviation (age and NIHSS score) or as $\mathrm{n}(\%)$.

Abbreviations: $\mathrm{ACl}$, anterior circulation infarction; $\mathrm{PCl}$, posterior circulation infarction; $C A D$, coronary artery disease; $P A D$, peripheral artery disease; BMI, body mass index; NIHSS, National Institutes of Health Stroke Scale.

was observed. Using the receiver-operating characteristic curve analysis (Figure 1), the cutoff value of baseline NIHSS score predicting NMC was 5 for anterior circulation infarction (area under the curve $=0.797 ; 95 \%$ CI: $0.73-0.86$; $P<0.001$ ) and 2 for posterior circulation infarction (area under the curve $=0.799 ; 95 \%$ CI: $0.66-0.93 ; P<0.001)$.

\section{Patients with anterior circulation infarction}

In 199 patients with anterior circulation infarction, smoking status (10\% versus $25 \%, P=0.02)$, hypercholesterolemia (18\% versus $39 \%, P=0.003$ ), and body mass index $\geq 25$ (41\% versus $56 \%, P=0.047$ ) were less frequent in patients with NMC, whereas a tendency was observed for higher frequency of chronic kidney disease in patients with NMC (34\% versus $22 \%, P=0.08$ ). Patients with NMC had a higher NIHSS score $(12.6 \pm 8.3$ versus $4.9 \pm 5.0 ; P<0.001)$ and baseline NIHSS score $>5(75 \%$ versus $22 \%, P<0.001)$. Stepwise logistic regression selected the following independent factors for NMC: NIHSS score $>5$ (OR: 6.3, 95\% CI: $2.80-14.14 ; P<0.001)$, smoking status (OR: 0.30, 95\% CI: $0.10-0.85 ; P=0.024$ ), hypercholesterolemia (OR: 0.24, 95\% CI: $0.09-0.61 ; P=0.003)$, and chronic kidney disease (OR: 3.4, 95\% CI: 1.45-7.94; $P=0.005$ ). 
Table 2 NMC observed in stroke patients (I08 NMC were observed in 79 patients)

\begin{tabular}{ll}
\hline & Cases (n) \\
\hline Neurological event & $\mathbf{4 8}$ \\
Ischemic stroke recurrence & 15 \\
Symptomatic intracranial hemorrhage & 14 \\
Seizure & 14 \\
Malignant cerebral infarction & 5 \\
Medical event & 60 \\
Post-stroke infections & 44 \\
Nosocomial pneumonia & 30 \\
Urinary tract infection & 12 \\
Acute cholecystitis & 1 \\
Septic shock & $\mathrm{I}$ \\
Other causes & 12 \\
Acute renal failure & 5 \\
Severe hematuria & $\mathrm{I}$ \\
Peripheral arterial embolism & $\mathrm{I}$ \\
Aortic dissection & $\mathrm{I}$ \\
Mesenteric ischemia & $\mathrm{I}$ \\
Symptomatic bradycardia & $\mathrm{I}$ \\
Gastrointestinal bleeding & $\mathrm{I}$ \\
Acute pulmonary edema & $\mathrm{I}$ \\
\hline
\end{tabular}

Abbreviation: NMC, neurological and medical complications.

\section{Patients with posterior circulation infarction}

In the 90 patients with posterior circulation infarction, demographic data, and vascular risk factors were not statistically different according to the presence of NMC (Table 3). Patients with NMC had a higher baseline NIHSS score and more frequently baseline NIHSS score $>2$, large vessel atherosclerosis,

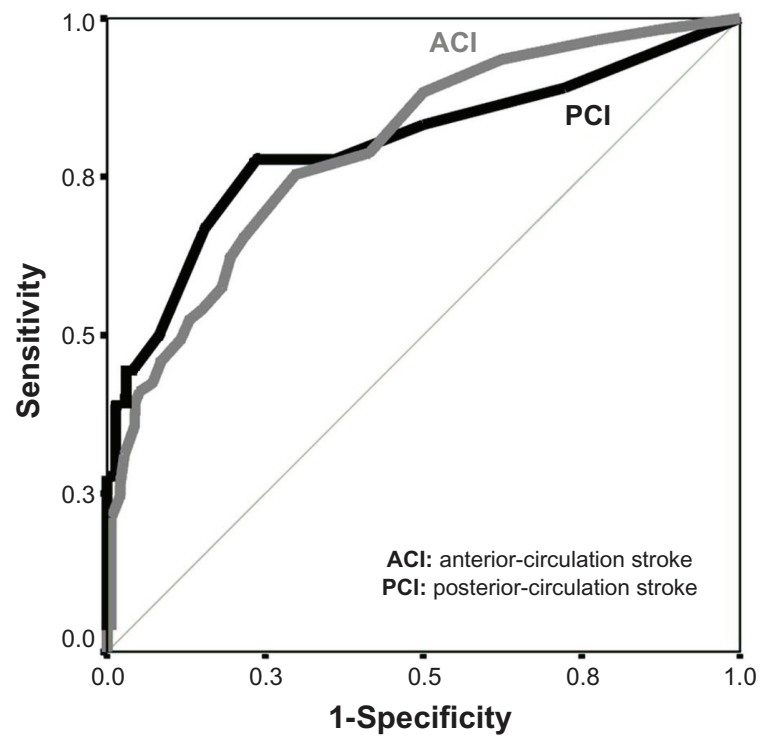

Figure I Receiver-operating characteristic curve analysis of National Institutes of Health Stroke Scale scores in patients with neurological and medical complications according to the type of ischemic stroke. and less frequently stroke with undetermined etiology. Stepwise logistic regression selected the following independent factors for NMC: NIHSS score $>2$ (OR: $8.2,95 \% \mathrm{CI}$ : 1.64-41.0; $P=0.01$ ), large vessel atherosclerosis (OR: 18.3, 95\% CI: $2.70-124.71 ; P=0.003)$ and stroke of undetermined etiology (OR: $0.11,95 \%$ CI: 0.01-0.97; $P=0.047$ ).

When considering only patients who experienced neurological events $(n=10)$, similar results were observed: these patients had a higher baseline NIHSS score $>2(100 \%$ versus $37 \%, P<0.001)$, more frequently large vessel atherosclerosis (50\% versus $7 \%, P=0.002$ ), and less frequently stroke with undetermined etiology ( $0 \%$ versus $42 \%, P=0.012)$. When considering only patients who experienced medical events $(\mathrm{n}=13)$, they had more frequently large vessel atherosclerosis (31\% versus $9 \%, P=0.05)$ and less frequently stroke with undetermined etiology ( $8 \%$ versus $43 \%, P=0.015)$, whereas there was a tendency for higher baseline NIHSS score $>2$ (69\% versus $40 \%, P=0.071)$.

\section{Patients with baseline NIHSS score of 0}

The 40 patients with posterior circulation infarction more frequently had a baseline NIHSS score of 0 than did patients with anterior circulation infarction $(20 \%$ versus $11 \%$, $P=0.001$ ); two posterior circulation infarction patients experienced NMC, whereas no NMC occurred in anterior circulation infarction patients in this population.

\section{Discussion}

The present study showed that an increased baseline NIHSS score in ischemic stroke patients was associated with an increased risk of NMC. This association applied to anterior circulation as well as posterior circulation stroke, although the cutoff value for the baseline NIHSS score predicting NMC was different between anterior circulation infarction and posterior circulation infarction patients. Indeed, despite a higher baseline NIHSS score in anterior circulation infarction patients than in posterior circulation infarction patients, the NIHSS score on admission can predict NMC, both in anterior circulation infarction and posterior circulation infarction patients, with a $6-8$-fold increase in risk. Our findings suggest that NIHSS assessment may be a useful approach to predict all NMC, even in patients with posterior circulation infarction, because it can alert the physician to the anticipated risk of NMC in an individual patient and can thus affect early decisions about further surveillance and diagnostics.

We showed that stroke patients experienced neurological and medical events in similar proportion. Our rate of complications is low compared with previous studies. Indeed, the 
Table 3 Demographic and clinical characteristics of patients with posterior circulation infarction $(n=90)$ according to the presence or absence of NMC

\begin{tabular}{|c|c|c|c|c|}
\hline & $\begin{array}{l}\text { All patients } \\
(\mathrm{n}=90)\end{array}$ & $\begin{array}{l}\text { NMC } \\
(n=18)\end{array}$ & $\begin{array}{l}\text { No NMC } \\
(n=72)\end{array}$ & $P$ value \\
\hline Age (years) & $67.6 \pm 14.7$ & $72.0 \pm 9.8$ & $66.6 \pm 15.9$ & 0.16 \\
\hline Men & $57(63)$ & $10(56)$ & $47(65)$ & 0.58 \\
\hline \multicolumn{5}{|c|}{ Previous main risk factors } \\
\hline Hypertension & $63(70)$ & $12(67)$ & $5 I(7 I)$ & 0.78 \\
\hline Diabetes mellitus & $23(26)$ & $7(39)$ & $16(22)$ & 0.22 \\
\hline Dyslipidemia & $30(33)$ & 7 (39) & $23(32)$ & 0.59 \\
\hline Active smoking & $18(20)$ & $3(17)$ & $15(21)$ & 1.00 \\
\hline CAD & $13(14)$ & I (6) & $12(17)$ & 0.45 \\
\hline PAD & $12(13)$ & $2(I I)$ & $10(14)$ & 1.00 \\
\hline Stroke & $23(26)$ & 7 (39) & $16(22)$ & 0.22 \\
\hline $\mathrm{BMI}>25 \mathrm{~kg} / \mathrm{m}^{2}$ & $44(49)$ & $8(44)$ & $36(50)$ & 0.79 \\
\hline $\begin{array}{l}\text { Alcohol consump- } \\
\text { tion }\end{array}$ & $12(13)$ & $2(\mathrm{II})$ & $10(14)$ & 1.00 \\
\hline $\begin{array}{l}\text { Chronic kidney } \\
\text { disease }\end{array}$ & $26(29)$ & $4(22)$ & $22(3 I)$ & 0.57 \\
\hline \multicolumn{5}{|l|}{ Baseline NIHSS } \\
\hline NIHSS score & $4.0 \pm 6.3$ & $10.9 \pm 11.0$ & $2.2 \pm 2.4$ & 0.004 \\
\hline NIHSS score $>2$ & $40(44)$ & $14(78)$ & $26(36)$ & 0.003 \\
\hline \multicolumn{5}{|c|}{ Causes of ischemic stroke } \\
\hline $\begin{array}{l}\text { Large vessel } \\
\text { atherosclerosis }\end{array}$ & II (I2) & 7 (39) & $4(6)$ & 0.001 \\
\hline Cardioembolic & $24(27)$ & $6(33)$ & $18(25)$ & 0.55 \\
\hline Lacunar & $10(11)$ & $2(11)$ & $8(I I)$ & 1.00 \\
\hline Undetermined & $34(38)$ & $I(6)$ & $33(46)$ & 0.001 \\
\hline Other & $7(8)$ & $2(I I)$ & $5(7)$ & 0.6 \\
\hline \multicolumn{5}{|c|}{ Therapeutics before hospitalization } \\
\hline $\begin{array}{l}\text { Antihypertensive } \\
\text { therapy }\end{array}$ & $60(67)$ & $12(67)$ & $46(64)$ & 1.00 \\
\hline $\begin{array}{l}\text { Antiplatelet } \\
\text { agents }\end{array}$ & $35(39)$ & $6(33)$ & $29(40)$ & 0.79 \\
\hline Anticoagulants & $4(4)$ & $2(11)$ & $2(3)$ & 0.18 \\
\hline Statins & $24(27)$ & $3(17)$ & $21(29)$ & 0.38 \\
\hline
\end{tabular}

Note: Results are presented either as the mean \pm standard deviation (age and NIHSS score) or as $n(\%)$.

Abbreviations: $C A D$, coronary artery disease; $P A D$, peripheral artery disease; $B M I$, body mass index; NIHSS, National Institutes of Health Stroke Scale; NMC, neurological and medical complications.

first studies which focused on NMC after stroke reported frequencies up to $90 \% .{ }^{6,20-22}$ More recently, the complication rate decreased, and it was estimated to be around $25 \% .2,23,24$ One explanation could be the better care of patients in stroke units, ${ }^{25}$ because improvement in outcome has been largely attributed to more effective prevention and treatment of NMC arising during stroke recovery. On the other hand, the heterogeneity of these results may be partly explained by the differences in study designs, criteria used for identifying complications, and also variations in identification and recording of complications. Chest infection is known to be one of the most frequent medical complications of stroke. ${ }^{4,21}$ Several investigations have studied demographic data and conventional risk factors associated with the risk of pneumonia in patients with stroke, and reported age older than 65 years, impaired consciousness, speech impairment, dysphagia, cognitive impairment, and brainstem strokes to be associated with development of chest infections. ${ }^{26-28}$ Urinary tract infections are also a frequent occurrence in patients with acute stroke. ${ }^{21,23}$ Similarly, increased age and stroke severity are independent predictors of urinary tract infections. ${ }^{29,30}$ The association of pneumonia with baseline NIHSS has been reported previously, ${ }^{30,31}$ but no cutoff value was determined. Recently, Chumbler et al found that NIHSS score at admission, associated with several other clinical variables, can identify stroke patients at higher risk of pneumonia. ${ }^{32}$

The NIHSS is increasingly being used as a measure of stroke severity among patients with ischemic stroke. However, previous studies have mainly included patients with anterior circulation infarction, with volumes of infarct lesions correlating well with NIHSS, ${ }^{33}$ whereas lesion volumes do not correlate with NIHSS score in patients with posterior circulation infarction. ${ }^{34}$ We found that NIHSS score was significantly associated with NMC in patients with posterior circulation infarction, albeit with a lower cutoff point than anterior circulation infarction. Despite posterior circulation infarction representing a heterogeneous group of strokes with various clinical presentations which cannot be captured as deficits on the NIHSS, our findings underscore the importance of using the NIHSS not only as a measure of stroke severity, but also as part of the assessment of risk of NMC. This may have some practical clinical implications to redirect preventive strategies in patients at risk because it can alert the physician to the anticipated risk of NMC in an individual patient. However, we also showed that patients with posterior circulation infarction (but not those with anterior circulation infarction) who had a baseline NIHSS score of 0 could experience NMC. Similar results have been reported by Sato et al to determine the cutoff baseline NIHSS score that predicts long-term outcome in anterior circulation versus posterior circulation ischemic strokes. ${ }^{35}$ This finding indicates that NIHSS score alone cannot be used to rule out the risk of NMC in posterior circulation infarction patients and that the NIHSS does not substitute for further surveillance and diagnostics.

We also found that medical events were significantly more frequent in patients with large vessel atherosclerosis and significantly less frequent in patients with stroke of "undetermined" etiology. It is well known that stroke patients suffering from large vessel atherosclerosis have a higher risk of morbidity from other clinical manifestations 
of atherosclerotic disease, such as myocardial infarction, angina, peripheral artery disease, and vascular death. ${ }^{36,37}$ Furthermore, the presence of large vessel atherosclerosis reflects inflammation, and there is evidence to suggest that systemic inflammation is predictive of poor outcome after stroke. For example, Whiteley et al showed that the C-reactive protein level was associated with both vascular and nonvascular deaths after stroke, independently of initial stroke severity. ${ }^{38}$

This study has several potential limitations. First, baseline NIHSS scoring was not performed in the emergency department but in our stroke unit. This may have biased our results, because patients could deteriorate during transfer from the emergency department to the stroke unit, although patients with a history of an acute ischemic cerebral event more than 6 hours earlier were excluded from the study. Furthermore, our data were obtained from a single academic hospital setting and therefore may not be generalizable to other settings. Our results are also obtained from a retrospective analysis in a small sample size, and therefore prospective validation is required before NIHSS score can be considered as a predictor of NMC.

In conclusion, despite some methodological limitations, the present study shows that, in ischemic stroke patients, baseline NIHSS score is associated with an increased risk of NMC during hospitalization. This association between baseline NIHSS and NMC applies to anterior circulation as well as posterior circulation strokes, although NIHSS appears to have limitations in the latter, because zero on the NIHSS does not equal the absence of NMC. The clinical significance of these findings requires further evaluation in larger prospective studies.

\section{Disclosure}

The authors report no conflicts of interest in this work.

\section{References}

1. Alawneh JA, Moustafa RR, Baron JC. Hemodynamic factors and perfusion abnormalities in early neurological deterioration. Stroke. 2009;40(6):e443-e450.

2. Weimar C, Roth MP, Zillessen G, et al; German Stroke Date Bank Collaborators. Complications following acute ischemic stroke. Eur Neurol. 2002;48(3):133-140.

3. Davalos A, Toni D, Iweins F, Lesaffre E, Bastianello S, Castillo J. Neurological deterioration in acute ischemic stroke: potential predictors and associated factors in the European Cooperative Acute Stroke Study (ECASS) I. Stroke. 1999;30(12):2631-2636.

4. Kumar S, Selim MH, Caplan LR. Medical complications after stroke. Lancet Neurol. 2010;9(1):105-118.

5. Rocco A, Pasquini M, Cecconi E, et al. Monitoring after the acute stage of stroke. A prospective study. Stroke. 2007;38(4):1225-1228.

6. Davenport RJ, Dennis MS, Wellwood I, Warlow CP. Complications after acute stroke. Stroke. 1996;27(3):415-420.
7. Kasner SE, Chalela JA, Luciano JM, et al. Reliability and validity of estimating the NIH Stroke Scale score from medical records. Stroke. 1999;30(8):1534-1537.

8. Lyden P, Raman R, Liu L, et al. NIHSS training and certification using a new digital video disk is reliable. Stroke. 2005;36(11):2446-2449.

9. Lyden P, Brott T, Tilley B. Improved reliability of the NIH stroke scale using video training: NINDS TPA stroke study group. Stroke. 1994;25(11):2220-2226.

10. Adams HP Jr, Davis PH, Leira EC, et al. Baseline NIH Stroke Scale score strongly predicts outcome after stroke: a report of the Trial of Org 10172 in Acute Stroke Treatment (TOAST). Neurology. 1999;53(1):126-131.

11. Kwiatkowski TG, Libman RB, Frankel M, et al. Effects of tissue plasminogen activator for acute ischemic stroke at one year. National Institute of Neurological Disorders and Stroke Recombinant Tissue Plasminogen Activator Stroke Study Group. $N$ Engl J Med. 1999;340(23):1781-1787.

12. Appelros P. Prediction of length of stay for stroke patients. Acta Neurol Scand. 2007;116(1):15-19.

13. Muir WK, Weir CJ, Murray GD, Povey C, Lees KR. Comparison of neurological scales and scoring systems for acute stroke prognosis. Stroke. 1996;27(10):1817-1820.

14. Kasner SE. Clinical interpretation and use of stroke scales. Lancet Neurol. 2006;5(7):603-612.

15. Bugnicourt JM, Chillon JM, Canaple S, Lamy C, Godefroy O. Stroke secondary prevention and blood pressure reduction: an observational study of the use of PROGRESS therapy. Fundam Clin Pharmacol. 2008;22(2):217-222.

16. Adams HP Jr, Bendixen BH, Kappelle LJ, et al. Classification of subtype of acute ischemic stroke. Definitions for use in a multicenter clinical trial. TOAST. Trial of Org 10172 in Acute Stroke Treatment. Stroke. 1993;24(1):35-41.

17. Levey AS, Coresh J, Balk E, et al; National Kidney Foundation. National Kidney Foundation practice guidelines for chronic kidney disease: evaluation, classification, and stratification. Ann Intern Med. 2003;139(2):137-147.

18. Bamford J, Sandercock P, Dennis M, Burn J, Warlow C. Classification and natural history of clinically identifiable subtypes of cerebral infarction. Lancet. 1991;337(8756):1521-1526.

19. De Marchis GM, Kohler A, Renz N, et al. Posterior versus anterior circulation strokes: comparison of clinical, radiological and outcome characteristics. J Neurol Neurosurg Psychiatry. 2011;82(1):33-37.

20. Kalra L, Yu G, Wilson K, Roots P. Medical complications during stroke rehabilitation. Stroke. 1995;26(6):990-994.

21. Johnston KC, Li JY, Lyden PD, et al. Medical and neurological complications of ischemic stroke: experience from the RANTTAS trial. Stroke.1998;29(2):447-453.

22. Langhorne P, Stott DJ, Robertson L, et al. Medical complications after stroke: a multicenter study. Stroke. 2000;31(6):1223-1229.

23. Bae HJ, Yoon DS, Lee J, et al. In-hospital medical complications and long-term mortality after ischemic stroke. Stroke. 2005;36(11): 2441-2245.

24. Hong KS, Kang DW, Koo JS, et al. Impact of neurological and medical complications on 3-month outcomes in acute ischaemic stroke. Eur J Neurol. 2008;15(12):1324-1331.

25. Stroke Unit Trialists' Collaboration. Organised inpatient (stroke unit) care for stroke. Cochrane Database Syst Rev. 2007;4:CD000197.

26. Sellars C, Bowie L, Bagg J, et al. Risk factors for chest infection in acute stroke: a prospective cohort study. Stroke. 2007;38(8):2284-2291.

27. Dziewas R, Ritter M, Schilling M, et al. Pneumonia in acute stroke patients fed by nasogastric tube. J Neurol Neurosurg Psychiatry. 2004;75(6):852-856.

28. Hilker R, Poetter C, Findeisen N, et al. Nosocomial pneumonia after acute stroke: implications for neurological intensive care medicine. Stroke. 2003;34(4):975-981.

29. Stott DJ, Falconer A, Miller H, Tilston JC, Langhorne P. Urinary tract infection after stroke. QJM. 2009;102(4):243-249. 
30. Aslanyan S, Weir CJ, Diener HC, Kaste M, Lees KR; GAIN International Steering Committee and Investigators. Pneumonia and urinary tract infection after acute ischaemic stroke: a tertiary analysis of the GAIN International trial. Eur J Neurol. 2004;11(1):49-53.

31. Weimar C, Mieck T, Buchthal J, Ehrenfeld CE, Schmid E, Diener HC; German Stroke Study Collaboration. German Stroke Study Collaboration. Neurologic worsening during the acute phase of ischemic stroke. Arch Neurol. 2005;62(3):393-397.

32. Chumbler NR, Williams LS, Wells CK, et al. Derivation and validation of a clinical system for predicting pneumonia in acute stroke. Neuroepidemiology. 2010;34(4):193-199.

33. Lövblad KO, Baird AE, Schlaug G, et al. Ischemic lesion volumes in acute stroke by diffusion-weighted magnetic resonance imaging correlate with clinical outcome. Ann Neurol. 1997;42(2):164-170.

34. Linfante I, Llinas RH, Schlaug G, Chaves C, Warach S, Caplan LR. Diffusion-weighted imaging and National Institutes of Health stroke scale in the acute phase of posterior-circulation stroke. Arch Neurol. 2001;58(4):621-628.
35. Sato S, Toyoda K, Uehara T, et al. Baseline NIH Stroke Scale Score predicting outcome in anterior and posterior circulation strokes. Neurology. 2008;70(2):2371-2377.

36. Burke GL, Evans GW, Riley WA, et al. Arterial wall thickness is associated with prevalent cardiovascular disease in middle-aged adults. The Atherosclerosis Risk in Communities (ARIC) Study. Stroke. 1995;26(3):386-391.

37. Touzé E, Varenne O, Chatellier G, Peyrard S, Rothwell PM, Mas JL. Risk of myocardial infarction and vascular death after transient ischemic attack and ischemic stroke: a systematic review and meta-analysis. Stroke. 2005;36(12):2748-2755.

38. Whiteley W, Jackson C, Lewis S, et al. Association of circulating inflammatory markers with recurrent vascular events after stroke: a prospective cohort study. Stroke. 2011;42(1):10-16.
Therapeutics and Clinical Risk Management

\section{Publish your work in this journal}

Therapeutics and Clinical Risk Management is an international, peerreviewed journal of clinical therapeutics and risk management, focusing on concise rapid reporting of clinical studies in all therapeutic areas, outcomes, safety, and programs for the effective, safe, and sustained use of medicines. This journal is indexed on PubMed Central, CAS,

\section{Dovepress}

EMBase, Scopus and the Elsevier Bibliographic databases. The manuscript management system is completely online and includes a very quick and fair peer-review system, which is all easy to use. Visit $\mathrm{http} / / / \mathrm{www}$.dovepress.com/testimonials.php to read real quotes from published authors.

Submit your manuscript here: http://www.dovepress.com/therapeutics-and-clinical-risk-management-journal 